\title{
Isolation and molecular identification of microorganisms isolated from soils contaminated with heavy metals in Mosul city
}

Sana Qasim ( $\sim$ Sana.evp11@student.uomosul.edu.iq )

University of Mosul College of Environmental Sciences and Technology https://orcid.org/0000-00021624-0717

Mazin N. Fadhel

University of Mosul

Mohammad I. Khalil

University of Mosul

\section{Research Article}

Keywords:

Posted Date: July 28th, 2021

DOl: https://doi.org/10.21203/rs.3.rs-747759/v1

License: (c) (i) This work is licensed under a Creative Commons Attribution 4.0 International License. Read Full License 


\section{Abstract}

This research is concerned with organisms isolated from soils contaminated with heavy metals in industrial and residential areas in the city of Mosul, the center of Nineveh Governorate, and the diagnosis of these organisms using molecular biology technique. Samples were collected from four locations in the city between the industrial area and residential neighborhoods.

Soil samples were analyzed and dilutions were prepared, then the dilutions were grown on potato extract and dextrose (PDA) medium for the development of fungi and Nutrient agar for bacterial development. The dilutions were planted by casting method by three replications, then the process of purifying the fungal and bacterial colonies was carried out using the traditional methods. For the purpose of diagnosing these pure colonies using PCR technique, colonies of fungi were grown on the medium of PDA, and bacteria were grown on the medium of nutritious broth.

As a result, nine fungal species were diagnosed, two of them are new undiagnosed genera that have been registered in the gene bank, four of them contain genetic mutations, and three of them are known and previously diagnosed fungi. As for bacteria, two new strains were isolated and registered in the gene bank among the four types that were diagnosed. And some of these genera exhibited severe resistance to antibiotics, while others showed moderate resistance, in contrast to the control, which was very sensitive to antibiotics.

\section{Introduction}

A "heavy metal" is any element that has metallic properties (such as luster, electrical and thermal conductivity), and a relatively high density. Although essential heavy metals are required in many biological processes such as growth and function at low concentrations, they are harmful if they exceed the required concentration. (Hughes and Poole, 1991; Bazzi et al., 2020).

High concentrations of toxic metals in soils are a serious environmental problem worldwide, which can pose significant risks to human health through various exposure pathways. Oral ingestion, inhalation of volatile and particulate matter, and dermal contact are the most important pathways of human exposure to metal-contaminated urban soils. Children are more likely to be exposed to toxic metals in urban soils than adults because they may absorb through the skin, ingest or inhale large amounts of toxic metals during their outdoor activities and play (Karim and Qureshi, 2014). The most toxic heavy metals to plants such as lead $(\mathrm{Pb})$, arsenic $(\mathrm{As})$,. cadmium $(\mathrm{Cd})$ and mercury $(\mathrm{Hg})$ are metals found in the soil, which are highly mobile and are immediately absorbed by plants. Also, copper $(\mathrm{Cu})$, chromium $(\mathrm{Cr})$, zinc $(\mathrm{Zn})$, selenium (Se), molybdenum (Mo), tin ( $\mathrm{Sn}$ ), and nickel ( $\mathrm{Ni})$, which cause environmental pollution and health risks (Dhalaria et al., 2020). (Rahman, 2020) stated in his study that pollution with heavy metals produced negative effects such as mutagenic, teratogenic and carcinogenic effects in humans and wildlife. 
Metal resistance is defined as the ability of an organism to survive and counteract metal toxicity by various mechanisms produced in direct. response to the metal species involved (Mehra \&Winge,1991; Prasenjit \& Sumathi, 2005 ) or that this resistance is due to changes to the genetic material through mutations or the addition of new genetic material (Bennett, 2008).

The term "antibiotics" was used for the first time in 1942 by the scientist Waksman, who defined antibiotics as metabolic substances produced by microorganisms that inhibit the growth of other microorganisms and do not affect the bacteria that produce them. Antibiotics target specific bacterial structures or processes, and may act by inhibiting growth, directly killing the organism, or by combining both mechanisms. (Manad, 2007; Aminov \& Mackie ,2007; Pal et al., 2017 ; Dweba et al., 2018).

Most heavy metals are non-degradable and persist in the environment, and many species have evolved resistance mechanisms to combat metal toxicity. Heavy metals can cause selective pressure on microbial populations leading to antimicrobial resistance through a mechanism called "co-selection" (Seiler and Berendonk, 2012; Li et al., 2017b).

This study aims to analyze soil samples contaminated with heavy metals to isolate and identify microorganisms (bacteria and fungi) thriving in this environment and investigate the sensitivity of isolated microorganism to antibacterial and antifungal agents respectively.

\section{Methods}

\section{Sample collection sites}

Samples were collected from four areas: the first and second from near a local electricity generator inside a residential area and within an industrial area, the third and fourth samples from near car repair and maintenance shops in a residential area and industrial area in the city, as shown in Figure (1). The sample collection process was carried out using a sterile drilling tool and sterile sample collection bags with a depth of (0-15) cm.

\section{Isolation}

The dilution method was used to isolate the organisms from the soil, by taking $10 \mathrm{~g}$ of soil sample and placing it in a sterile glass beaker containing $90 \mathrm{ml}$ of sterile distilled water and shaking it well to obtain a dilution $\left(10^{-3}\right)$. The dishes were incubated upside down at $28^{\circ} \mathrm{C}$ for 7 days for PDA medium, and at $37^{\circ} \mathrm{C}$ for one day for nutrient agar (NA) medium. Then the colonies were purified by repeated transfer on the culture media, and the purified cultures were kept on slant, kept in the refrigerator, renewed every month and used when needed. (Meysami and Baheri, ,2003).

\section{Diagnosis}

Fungal and bacterial species isolated from soil samples were characterized by Polymerase Chain Reaction, (PCR), by amplifying the Internal transcribed spacer (ITS) region preserved in the fungal 
DNA (Altaee , 2018 ; Abdulla , 2020).

\section{Study of Heavy metals Effect on the growth of living organisms (bacteria and fungi)}

Two minerals were selected for the study, namely lead and zinc, and the development of microorganisms on different concentrations of these minerals and observation of the changes that occur in them and their resistance to these concentrations. Fungi were cultured in PDA medium containing heavy metal separately at concentrations of $(25,50,100,150,200,300,400,500,600,700,800,900,1000)$ ppm and incubated for 7 days. The fungus with the highest growth on the metal was taken and grown with different concentrations of the antifungal (nystatin) and compared with the fungus grown without metal as a control. Bacteria were cultured in nutrient broth and incubated for one day, then cultured on a petri dish containing NA by wiping the plate with a cotton swap on each plate, then drilling in the culture medium to apply the concentrations of minerals In it, using a micropipette with a volume of $100 \mu \mathrm{l}$, and incubated for one day .

\section{Cultivation of living organisms with Antibiotics}

A spore suspension of mushrooms was made and distributed on the plate containing the medium of the PDA, then digging was made and the antifungal (nystatin) was placed in it at concentrations of $(25 \%$, $50 \%, 75 \%, 100 \%)$ and the dish was incubated in the fungi incubator for seven days. As for the bacteria, the plate containing the agar-nutrient medium was wiped with bacteria grown on the broth fed with cotton, then antibiotic tablets were distributed on the surface of the medium and incubated in the bacteria incubator for one day (Bhalodia et al., 2011; Tokarzewskiet et al., 2012).

\section{Results And Discussion}

The results of the current study of the organisms isolated from the soil showed the genera shown in Tables (1 and 2).

\section{Study of resistance of microorganisms to heavy metals}

Despite the importance of mineral elements to organisms for growth and function such as potassium and magnesium and some trace elements such as manganese, iron, copper, zinc and molypodium, high concentrations of some of them are toxic and harmful (Hughes and Poole, 1991; Osredkar and Šuštar, 2011). , zinc and lead were chosen in the study based on previous research on heavy metals in the city of Mosul, the most recent of which was a study (Znad and Al-Sinjary, 2020). Low concentrations of the mineral, as shown in pink in Tables ( 3 and 4), through an increase in the diameter of the colony and an increase in its number, then the growth gradually decreased until the death of the organism ,This is consistent with the study (Osredkar and Šustar, 2011; Raftos and Radford, 2015) which indicate that minerals at low concentrations are nutritious to the organism, but their toxicity appears by increasing these concentrations. Some species were slightly inhibited, but remained resistant even at a concentration of 1000 ppm of metal, and this is in line with what was stated (Pal et al., 2017) where 
organisms can acquire resistance as a result of the presence of some metals in high concentrations of more than a few thousand $\mathrm{mg} / \mathrm{kg}$ (ppm).

Fungi are highly resistant compared to many other microorganisms due to their high tolerance to high temperatures and acidity, low nutrients, and high levels of minerals but this adaptation and resistance is demonstrated by changing the abundance and structure of the fungal community (El Ghait, 2015; Lin et al. , 2020; Zhao et al., 2019), and this appeared in our study in a change in the color and density of hyphae and colonies for many species. These studies also indicated that the fungi of the type Aspergillus and Penicillium were more resistant to heavy metals than the rest of the species, in addition to their ability to biologically absorb some metals such as cadmium, lead and nickel, and their positive correlation with low levels of zinc and lead contamination, which is consistent with the results of the current study.

Heavy metals in trace amounts are necessary for the growth of bacteria, but they can be stress factors affecting the synthesis of proteins in them. (Zhou et al., 2015). Bacteria were cultured with different concentrations of heavy metals starting from 25 to $2000 \mathrm{ppm}$. The three bacterial species isolated from contaminated soil, in addition to bacteria isolated from contaminated aquatic environment, were sensitive to zinc at small concentrations, starting from a concentration of $100 \mathrm{ppm}$, as shown in Tables ( 3 and 4) In contrast to lead, which had a positive effect on it at low concentrations of the metal, which is consistent with most studies, but it showed a negative effect starting from a concentration of $1400 \mathrm{ppm}$ for three races, and the fourth race remained resistant to the rise in metal concentration, and this may be a result in response to toxic metal stress and developing some survival mechanisms in their genome, such as producing a variety of enzymes and proteins that help them overcome this stress, as explained in his study (Das et al., 2016).

In general, the bacterial species did not show a strong resistance to metals. This may be due to the fact that all bacterial species in this study are Gram-positive bacteria, and unlike Gram-negative bacteria, as stated in the study (Nguyen et al., 2019), they tend to produce higher levels of resistance. Compared to valued positive bacteria .

\section{Cultivation of microorganisms with antibiotics}

The results of the current study, as shown in Figure (2), showed that the species Aspergillus tubingensis, Penicillium consobrinum SANA-3, Aspergillus sp E30 were almost moderately resistant, while Fungal sp. SANA-5 was resistant without metal and in all antifungal concentrations, while it was sensitive with the presence of metal. Its explanation may be what was stated in a study (Morkunas et al., 2018, Rahman and Singh, 2019) where heavy metals have negative effects on the growth of microbes. Soil and fungi, the inhibition of fungal growth comes as a result of the accumulation of heavy metals in the fungal cells.

Alternaria alternate isolate from non-contaminated environment (as a control) was cultured with antifungal. The results showed that the fungus was very sensitive to the antifungal and much more than the fungi isolated from the contaminated environment. This is consistent with what was stated in a 
previous study which reported that isolates from contaminated soil are more resistant than isolates from unpolluted environment (Raftos and Radford, 2015).

With regard to culturing bacteria with antibiotic tablets, the results showed resistance of all strains to amoxicillin and metronidazole, and Streptococcus bacteria resistant to tetracycline, gentmycin and azithromycin as well. As shown in Table (5) and by comparing the damping diameter with the special tables in some sources (Bhalodia et al., 2011; Tokarzewski et al., 2012; Aditi et al., 2017)

Streptococcus bacteria, which had the highest resistance among the bacterial genera under investigation, is a bacterium isolated from contaminated water. This resistance is explained by (Dweba, Zishiri and El Zowalaty, 2018) in that these bacteria is characterized by its ability to rapidly develop antimicrobial resistance. The reason for this resistance may be Also, the biological availability of heavy metals in water is more than their biological availability in soil. It was mentioned (Glibota et al., 2020) in a study that soil and its quality have an impact on the biological availability of minerals and the presence of linking elements as well as bacterial and biological groups and the concentration of organic gases such as methane and ethane and the formation of complexes .

To determine the severity of bacterial resistance to antibiotics, the multiple antibiotic resistance (MAR) index was adopted, which came in the study (Mandal et al., 2016) and (Dweba et al., 2019). whereas

MAR = the number of antibiotics that the isolate showed resistance to / the number of total antibiotics exposed to the isolate.

It is interpreted as

MAR $\geq 0.2$ as increased risk of antibiotic contamination.

MAR $<0.2$ Low risk.

The results of the isolates were between (0.5-0.2), which indicates a high risk of antibiotic contamination, and that all these strains originated from a high-risk source of contamination.

\section{Conclusion}

Heavy metals, a large part of them are naturally present, but they are toxic only if they are soluble in water and bioavailable, and this comes as a result of human activities most of the time. The current results, in addition to the results of previous studies, show an overlap between heavy metal contamination and its resistance by microorganisms and the resistance of this organism to antibiotics, as heavy metals are an important factor in making organisms resistant to antibiotics. The outcomes of this study will significantly contribute to the current body of knowledge of research towards public and veterinary health especially in developing countries and highlight the importance of fulfilling one-health attitudes to lower the ongoing spread of antimicrobial resistance. 


\section{Declarations}

\section{Compliance with Ethical Standards:}

No funding was granted to this project.

\section{Conflict of interest:}

Sana Alkazaz declares that she has no conflict of interest. Mazin fadhel declares that he has no conflict of interest. Mohammed Khalil declares that he has no conflict of interest.

\section{References}

Abdullah, O. Abdul-Jabbar (2020), Fungal bioremediation of polycyclic aromatic hydrocarbons in soils contaminated with crude oil, Master's thesis, College of Environmental Sciences and Technologies, University of Mosul.

Aditi, F. Y., Rahman, S. S. and Hossain, M. M. (2017) 'A Study on the Microbiological Status of Mineral Drinking Water', The Open Microbiology Journal, 11(1), pp. 31-44. doi: 10.2174/1874285801711010031.

Altaee, M. I. Khalil (2018), Molecular Biology, Evidence for Polymerase Chain Reaction (PCR), Azariat AlKitab and Graduate Studies House - Alexandria.

Aminov, R. I. and Mackie, R. I. (2007) 'Evolution and ecology of antibiotic resistance genes', FEMS Microbiology Letters, 271(2), pp. 147-161. doi: 10.1111/j.1574-6968.2007.00757.x.

Bazzi, W. et al. (2020) 'Heavy Metal Toxicity in Armed Conflicts Potentiates AMR in A. baumannii by Selecting for Antibiotic and Heavy Metal Co-resistance Mechanisms', Frontiers in Microbiology, 11(February), pp. 1-12. doi: 10.3389/fmicb.2020.00068.

Bennett, P. M. (2008) 'Plasmid encoded antibiotic resistance: Acquisition and transfer of antibiotic resistance genes in bacteria', British Journal of Pharmacology, 153(SUPPL. 1), pp. 347-357. doi: 10.1038/sj.bjp.0707607.

Bhalodia, N. R., Nariya, P. B. and Shukla, V. J. (2011) 'Antibacterial and antifungal activity from flower extracts of Cassia fistula L.: An ethnomedicinal plant', International Journal of PharmTech Research, 3(1), pp. 160-168. doi: 10.4103/2231-4040.82956.

Das, S., Dash, H. R. and Chakraborty, J. (2016) 'Genetic basis and importance of metal resistant genes in bacteria for bioremediation of contaminated environments with toxic metal pollutants', Applied Microbiology and Biotechnology, 100(7), pp. 2967-2984. doi: 10.1007/s00253-016-7364-4.

Dhalaria, R. et al. (2020) 'Arbuscular mycorrhizal fungi as potential agents in ameliorating heavy metal stress in plants', Agronomy, 10(6). doi: 10.3390/agronomy10060815. 
Dweba, C. C., Zishiri, O. T. and El Zowalaty, M. E. (2018) 'Methicillin-resistant staphylococcus aureus: Livestock-associated, antimicrobial, and heavy metal resistance', Infection and Drug Resistance, 11, pp. 2497-2509. doi: 10.2147/IDR.S175967.

Dweba, C. C., Zishiri, O. T. and El Zowalaty, M. E. (2019) 'Isolation and molecular identification of virulence, antimicrobial and heavy metal resistance genes in livestock-associated methicillin-resistant Staphylococcus aureus', Pathogens, 8(2). doi: 10.3390/pathogens8020079.

El-Gheit, e , Yassin El Sayed Zeidan, Maysa Mohamed Ali Mansour. (2015) 'Experimental Study', Alexandria Journal of Scientific Exchange (Volume 36, Issue 22.(

Glibota, N. et al. (2020) 'Genetic determinants for metal tolerance and antimicrobial resistance detected in bacteria isolated from soils of olive tree farms', Antibiotics, 9(8), pp. 1-11. doi:

10.3390/antibiotics9080476.

Hughes, M. N. and Poole, R. K. (1991) 'Metal speciation and microbial growth - The hard (and soft) facts', Journal of General Microbiology, 137(4), pp. 725-734. doi: 10.1099/00221287-137-4-725.

Karim, Z. and Qureshi, B. A. (2014) 'Health Risk Assessment of Heavy Metals in Urban Soil of Karachi, Pakistan', Human and Ecological Risk Assessment, 20(3), pp. 658-667. doi:

10.1080/10807039.2013.791535.

Li, L. G., Xia, Y. and Zhang, T. (2017) 'Co-occurrence of antibiotic and metal resistance genes revealed in complete genome collection', ISME Journal, 11(3), pp. 651-662. doi: 10.1038/ismej.2016.155.

Lin, Y. et al. (2020) 'Adaptation of soil fungi to heavy metal contamination in paddy fields-a case study in eastern China', Environmental Science and Pollution Research, 27(22), pp. 27819-27830. doi: 10.1007/s11356-020-09049-9.

Manad, Ahmed (2007), Effect of mercury pollution on the spread of soil fungi in Azaba region, PhD thesis, Faculty of Science, Mentouri University of Constantine.

Mandal, S., Nath Das, S. and Mandal, M. (2016) 'Plasmid Mediated Antibiotic and Heavy Metal CoResistance in Bacterial Isolates from Mahananda River Water (Malda, India)', Translational Medicine, 06(04), pp. 6-11. doi: 10.4172/2161-1025.1000185.

Mehra, R. K. and Winge, D. R. (1991) 'Metal ion resistance in fungi: Molecular mechanisms and their regulated expression', Journal of Cellular Biochemistry, 45(1), pp. 30-40. doi: 10.1002/jcb.240450109.

Meysami, P., \& Baheri, H. (2003). Pre-screening of fungi and bulking agents for contaminated soil bioremediation. Advances in Environmental Research, 7(4), 881-887.

Morkunas, I., Woźniak, A., Mai, V. C., Rucińska-Sobkowiak, R., \& Jeandet, P. (2018). The role of heavy metals in plant response to biotic stress. Molecules, 23(9), 2320 
Nguyen, C. C. et al. (2019) 'Association between heavy metals and antibiotic-resistant human pathogens in environmental reservoirs: A review', Frontiers of Environmental Science and Engineering, 13(3). doi: 10.1007/s11783-019-1129-0.

Osredkar, J., \& Sustar, N. (2011). Copper and zinc, biological role and significance of copper/zinc imbalance. J Clinic Toxicol S, 3(2161), 0495.

Pal, C. et al. (2017) Metal Resistance and Its Association With Antibiotic Resistance. 1st edn, Advances in Microbial Physiology. 1st edn. Elsevier Ltd. doi: 10.1016/bs.ampbs.2017.02.001.

Prasenjit, B., \& Sumathi, S. (2005). Uptake of chromium by Aspergillus foetidus. Journal of Material Cycles and Waste Management, 7(2), 88-92.

Raftos, D. and Radford, J. (2015) 'BIOACCUMULATION OF HEAVY METALS BY FUNGI', INTERNATIONAL JOURNAL OF ENVIRONMENTAL CHEMISTRY \& CHROMATOGRAPHY, 14(2), pp. 40-43.

Rahman, Z. (2020) 'An overview on heavy metal resistant microorganisms for simultaneous treatment of multiple chemical pollutants at co-contaminated sites, and their multipurpose application', Journal of Hazardous Materials, 396(February), p. 122682. doi: 10.1016/j.jhazmat.2020.122682.

Seiler, C. and Berendonk, T. U. (2012) 'Heavy metal driven co-selection of antibiotic resistance in soil and water bodies impacted by agriculture and aquaculture', Frontiers in Microbiology, 3(DEC). doi: 10.3389/fmicb.2012.00399.

Tokarzewski, S., Ziółkowska, G. and Nowakiewicz, A. (2012) 'Susceptibility testing of Aspergillus niger strains isolated from poultry to antifungal drugs - A comparative study of the disk diffusion, broth microdilution (M 38-A) and Etest ${ }^{\circledR}$ methods', Polish Journal of Veterinary Sciences, 15(1), pp. 125-133. doi: 10.2478/v10181-011-0123-7.

Zhou, Y. et al. (2015) 'Combined toxic effects of heavy metals and antibiotics on a Pseudomonas fluorescens strain ZY2 isolated from swine wastewater', International Journal of Molecular Sciences, 16(2), pp. 2839-2850. doi: 10.3390/ijms16022839.

Znad, S. R. and Al-Sinjary, M. N. (2020) 'Assessment of heavy metal pollution of industrial zones in mosul city', Plant Archives, 20(August), pp. 256-263.

\section{Tables}

Tables 1-5 are available in the Supplementary Files.

\section{Figures}




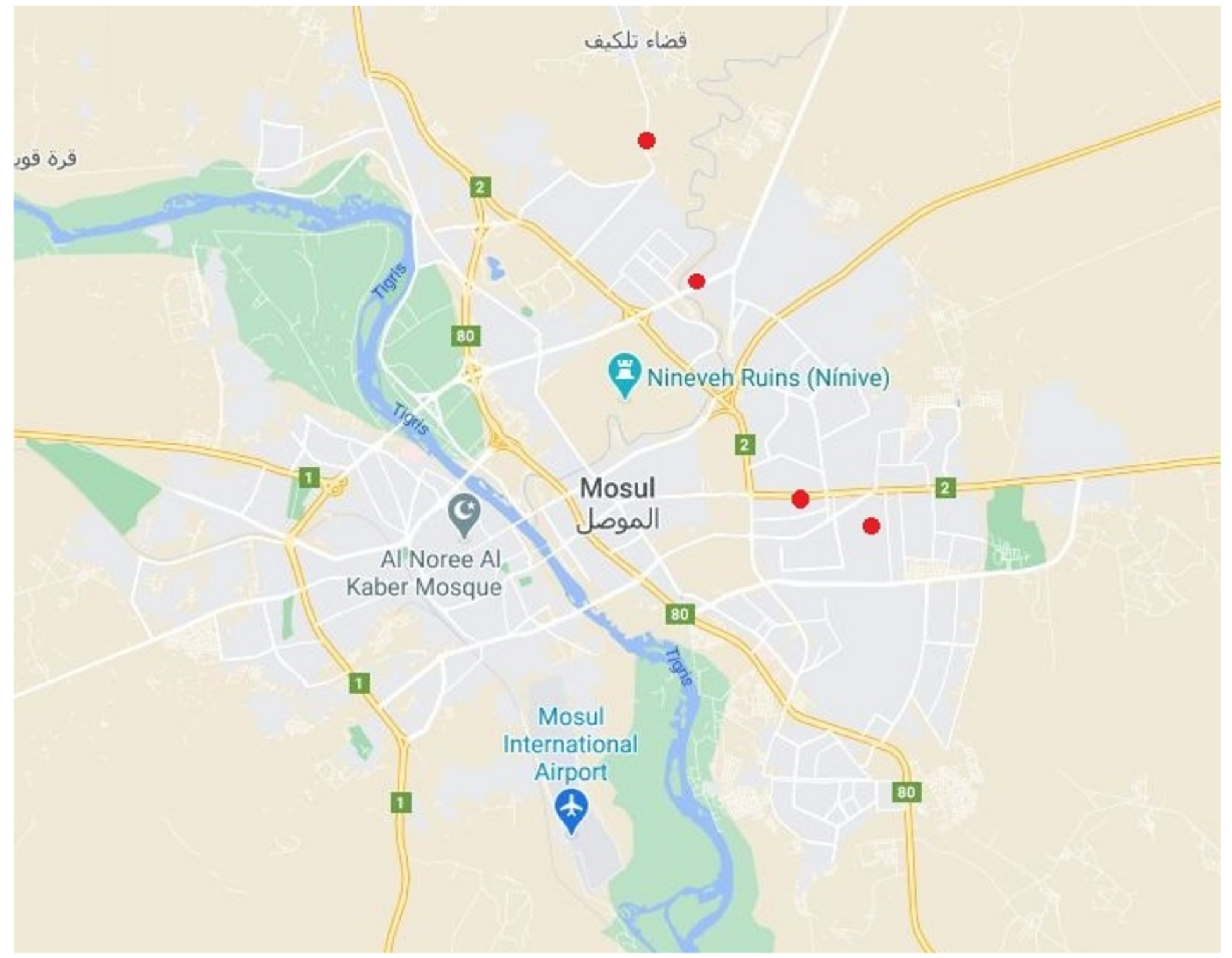

\section{Figure 1}

Sample collection sites in the city of Mosul 


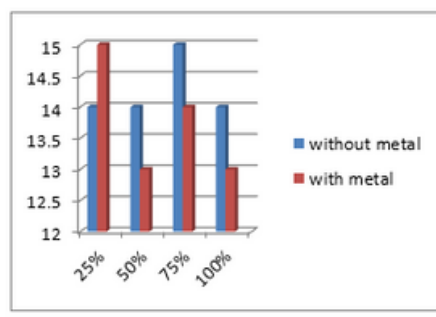

Aspergillus Tubingensis with nystatin

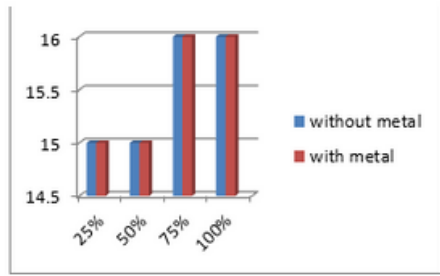

Aspergillus sp. E30 with nystatin

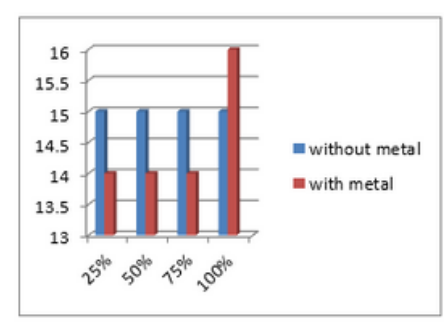

Penicillium Consobrinum SANA-3 with nystatin

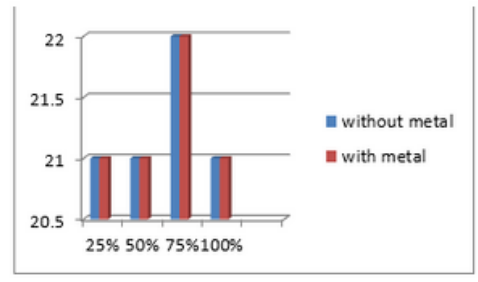

Fungal sp. SANA-4 with nystatin

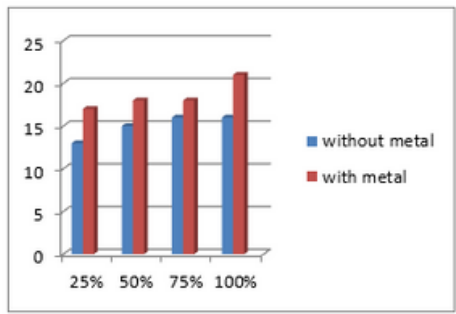

Fungal sp. SANA-5 with nystatin

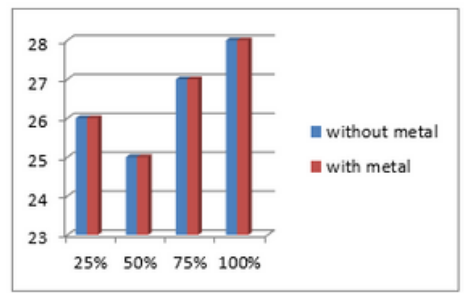

Aspergillus Recurvatus with nystatin

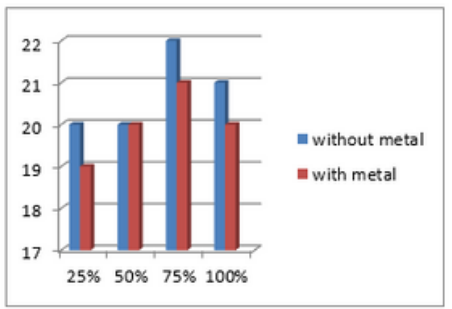

Aspergillus Niger with nystatin

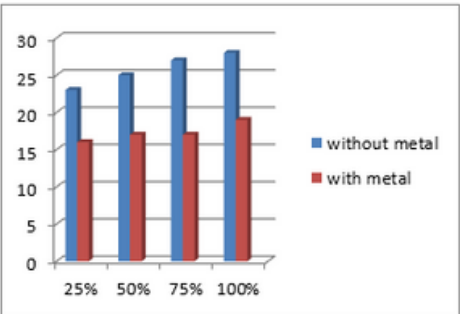

Aspergillus Niveus with nystatin

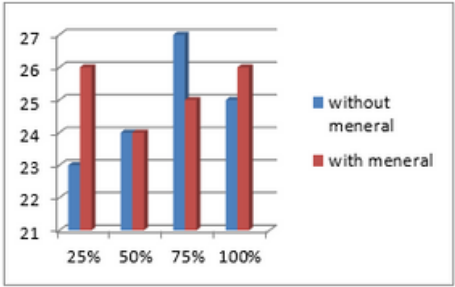

Pinicellum Consobrinum with nystatin

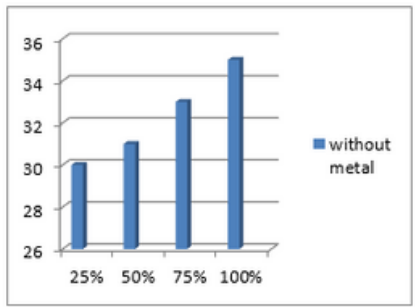

Alternaria Alternate with nystatin

Figure 2

Diameter of inhibition when cultivating fungal species with antifungal.

\section{Supplementary Files}

This is a list of supplementary files associated with this preprint. Click to download.

- ListofTables.docx

- Supplementarydatafile.docx 